\title{
Imagens periféricas: os Estudos Culturais e o Terceiro Cinema
}

\author{
Angela Prysthon 1 \\ Universidade Federal de Pernambuco \\ pryston@uol.com.br
}

\begin{abstract}
RESUMO: Este artigo pretende apresentar algumas notas sobre as possibilidades de conexão entre o campo dos Estudos Culturais e o Cinema contemporâneo. A intenção é tanto verificar como a própria configuração do cinema (especialmente aqueles filmes produzidos na periferia mundial ou aquilo que ainda pode ser chamado de Terceiro Cinema) demanda o olhar interdisciplinar que caracteriza a empresa metodológica dos Estudos Culturais, como também encontrar em alguns traços comuns que definem o cinema periférico novos desafios e inquietações para a teoria da cultura contemporânea. Para efetivar essa dupla operação, começaremos por apresentar muito panorâmica e resumidamente o surgimento dos Estudos Culturais e as transformações ocorridas ao longo dos últimos cinqüenta anos na área, associando posteriormente essa trajetória à consolidação progressiva do circuito cinematográfico das margens do capitalismo.
\end{abstract}

Palavras-chave: Estudos Culturais - Terceiro Cinema - Cultura contemporânea

ABSTRACT: This article explores the possibilities of connection between the field of Cultural Studies and contemporary cinema. The purpose is to verify how the very configuration of cinema (specially those films produced in the world periphery - or more specifically what we could still call "Third Cinema") demands the interdisciplinary approach that characterizes Cultural Studies. But there is also the intention to find in the common traces that define peripheral cinema new challenges and preoccupations for contemporary cultural theory. To perform this double operation, we present an abridged panorama of the history of Cultural Studies, describing its main transformations and convergences in the last fifty years, associating this trajectory to the progressive consolidation of the cinematographic circuit in the margins of capitalism.

Keywords: Cultural Studies - Third Cinema - Contemporary Culture

RESUMÉN: Este artículo pretende presentar algunas notas sobre las posibilidades de conexión entre el campo de los Estudios Culturales y el cine contemporáneo. La intención es verificar como la propia configuración del cine (especialmente aquellas películas producidas en la periferia mundial, o aquello que aún puede ser llamado de Tercer Cine) demanda la mirada interdisciplinaria que caracteriza la empresa metodológica de los Estudios Culturales, como también, a partir de algunos trazos comunes que definen el cine periférico, encontrar nuevos desafios para la teoría de la cultura contemporánea. Para efectuar esa doble operación, empezaremos por

${ }^{1}$ Professora do programa de pós-graduação da UFPE. 
presentar panorámica y resumidamente el surgimiento de los Estudios Culturales y las transformaciones ocurridas al largo de los últimos cincuenta años en el área, asociando esa trayectoria a la consolidación progresiva del circuito cinematográfico de las márgenes del capitalismo.

Palabras-llave: Estudios Culturales - Tercer Cine - Cultura
contemporánea

RESUMÉ : Cet article présente quelques notes sur les connections possibles entre le champs des Etudes Culturelles et le Cinéma contemporanein. $L$ 'intention est à la fois de vérifier comment la propre configuration du cinéma (en particulier les films produits dans la périphérie mondiale ou ce que l'on peutencore appelé " Tiers Cinéma 》) nécessite l'oeil interdisciplinaire qui caractérise l'entreprise métodologique des Etudes Culturelles, mais aussi de trouver les points communs qui définissent les nouveaux défis du cinéma périphérique et les nouvelles préoccupations de la théorie de la culture contemporaine. Pour réaliser cette double opération, nous commencerons en présentant de manière panoramique et résumée l'apparition des Etudes Culturelles et les transformations apparues dans ce domaine pendant les cinquante dernières années, associant par la suite cette trajectoire à la consolidation progressive du circuit cinématographique aux marges du capitalisme.

Mots-clés: Etudes Culturelles - Tiers Cinéma - Culture contemporaine

Este artigo pretende apresentar algumas notas sobre as possibilidades de conexão entre o campo dos Estudos Culturais e o Cinema contemporâneo. A intenção é tanto verificar como a própria configuração do cinema (especialmente aqueles filmes produzidos na periferia mundial ou aquilo que ainda pode ser chamado de Terceiro Cinema) demanda o olhar interdisciplinar que caracteriza a empresa metodológica dos Estudos Culturais, como também encontrar em alguns traços comuns que definem o cinema periférico novos desafios e inquietações para a teoria da cultura contemporânea. Para efetivar essa dupla operação, começaremos por apresentar muito panorâmica e resumidamente o surgimento dos Estudos Culturais e as transformações ocorridas ao longo dos últimos cinqüenta anos na área, associando posteriormente essa trajetória à consolidação progressiva do circuito cinematográfico das margens do capitalismo. 


\section{Percursos iniciais}

The desire called Cultural Studies is perhaps best approached politically and socially as the project to constitute a "historic bloc", rather than theoretically a floor plan for a new discipline. Fredric Jameson, "On Cultural Studies.

Os Estudos Culturais aparecem como um campo de estudos na GrãBretanha derivado de uma corrente chamada leavisismo, a partir do trabalho de F.R Leavis. O leavisismo foi uma tentativa de redisseminar o agora chamado "capital cultural" (Bourdieu) e para isso Leavis propunha usar o sistema educacional para distribuir mais amplamente (para todas as classes) conhecimento e apreciação literários baseados numa "grande tradição", no cânone da alta cultura. Apesar da influência de Leavis, tanto na prática (através da absorção de suas idéias nas escolas britânicas durante a expansão do sistema educacional nos anos 50 e 60), como na teoria, os dois representantes mais destacados desse início dos EC vão lidar de maneira diferente com essa idéia de "grande tradição". Richard Hoggart e Raymond Williams, ambos oriundos das classes trabalhadoras inglesas, tiveram uma relação ambivalente com o leavisismo: por um lado, concordavam que os textos canônicos eram mais ricos que a cultura de massas (combatida pelo leavisismo), por outro, reconheciam que o leavisismo apagava ou não chegava a entrar em contato com as formas culturais compartilhadas pelas classes trabalhadoras. Hoggart, com The Uses of Literacy (1957), e Williams, com Culture and Society (1958), vão estabelecer novas formas de analisar a cultura da classe operária. Um terceiro texto forma parte dos fundamentos dos EC, The making of the english working-class (1968), de E. P. Thompson. Nele, o historiador vai argumentar que a identidade da classe operária vai ter sempre um componente político e conflitual, independente de valores e interesses culturais particulares.

Ao lado dessas obras fundadoras, o surgimento do Center for Contemporary Cultural Studies (CCCS) na Universidade de Birmingham, Inglaterra, vai ser crucial para a institucionalização dos EC. A partir do Centro, uma série de jovens teóricos começa a explorar seriamente as funções políticas da cultura e se interessar de maneira mais sistemática pelas manifestações da cultura de massa. Com uma orientação claramente marxista, alguns conceitos e teóricos se destacam como grandes influências para os primeiros representantes dos EC: o conceito de 
hegemonia, por exemplo, associado a Gramsci, vai ser central para descrever as relações de dominação nem sempre aparentes na sociedade. Também derivado de uma concepção gramsciana, o termo subalterno sintetiza um dos principais focos de interesse dos EC, não apenas nos seus primórdios, como também na sua configuração atual. Os trabalhos da escola de Frankfurt sobre a Indústria Cultural também vão ter um papel relevante para a constituição do campo dos EC. Há uma série de afinidades entre a visão macro dos frankfurtianos sobre a sociedade e os EC, embora a teoria crítica alemã negligencie um aspecto essencial para os EC: as formas nas quais a indústria cultural, mesmo a serviço do capital, pode propiciar oportunidades para a criatividade individual e coletiva.

Além do marxismo, a semiótica também vai formar a base dos EC, especialmente a partir do final dos anos 6o. Stuart Hall aparece como a figura cardeal de uma abordagem mais estruturalista do campo dos EC, na qual o enfoque vai para o exame atento de práticas significantes e processos discursivos. Evidentemente as duas tendências se entrecruzam permanentemente (esse entrecruzamento sendo, aliás, a característica mais seminal dos EC) e seria impreciso separar tão radicalmente duas trincheiras, uma culturalista (com ênfase nas formas de vida, ou "estruturas de sentimento", como diria Williams) e outra estruturalista (semiótica).

Demonstrando ser uma possibilidade de conexão entre essas duas perspectivas, o marxismo estrutural de Louis Althusser representa outra linha proeminente na lista das influências mais acentuadas para os EC, através da sua teorização sobre a ideologia. Os EC estabelecem um diálogo intenso com a teoria francesa, a ponto de poderem ser definidos justamente como um território de fronteira entre as idéias estruturalistas (e pós-estruturalistas) e os fundamentos marxistas. Além da influência de Althusser, poderíamos mencionar Foucault, Barthes, Lyotard e Derrida como algumas das figuras-chave da teoria francesa a serem apropriadas pelos EC, especialmente a partir dos anos 80. Essa absorção do estruturalismo, da semiologia e do pós-estruturalismo franceses vai servir para uma reorientação dos EC:

Com o tempo, Birmingham vai absorvendo as novas questões trazidas especialmente pelos pensadores franceses como Foucault, de Certeau, Bourdieu etc, passam do estudo das comunidades articulados como classes ou sub-culturas - para o estudo dos grupos 
étnicos, de mulheres, raciais e tornam-se a voz do outro na academia, absorvendo assim um contingente expressivo de antropólogos, sem entretanto abrir mão, da criação de novos cruzamentos intelectuais e institucionais que produzam o efeito político de expandir a sociedade civil. (HOLLANDA, 1996)

Essa associação dos EC com a teoria francesa nos leva a uma outra, talvez ainda mais dominante, com os conceitos relacionados ao pós-moderno (muitos deles derivados das teorias francesas). Aliás, a primeira fase de delimitação do conceito de pós-moderno/pós-modernismo coincide com o florescimento do chamado (em termos bem gerais) pós-estruturalismo francês, o que resulta na subseqüente e freqüente associação da terminologia do último à construção do primeiro. A arte e a cultura pós-modernistas implicam na prática da citação, na recuperação lúdica do passado, na des-hierarquização, no des-centramento das formas; e quase todos os filósofos franceses pós-1960 (Foucault, Derrida, Barthes, Guattari, Deleuze, Baudrillard, Lyotard...), vale lembrar que lidando com objetos, perspectivas e graus de complexidade muito diferentes entre si, chegaram a analisar discursos e sociedades sob o filtro de noções como des-centramento, fragmentação dos sujeitos e das experiências, esquizofrenia, micropolitização do social, etc.

A intersecção entre pós-modernismo e pós-estruturalismo se intensificou com a conhecida e discutida proposição de Jean-François Lyotard (1979), que começa a definir o pós-moderno no fim dos anos 70 e início dos anos 80. Lyotard afirma que a pós-modernidade é a época onde já não existem mais metanarrativas, onde os jogos de linguagem, múltiplos e heteromórficos predominam numa sociedade pontilhista, na qual é impossível estabelecer regras gerais. A filosofia francesa desta época, em geral, condenou os esquemas interpretativos absolutos (como o marxista e freudiano, por exemplo) e se baseou em uma crítica dos procedimentos racionais ocidentais, mesmo que não nomeassem diretamente o pós-moderno/pós-modernismo. A conseqüência mais imediata deste tipo de corte epistemológico e de enfoque foi a inclusão de nomes como os de Foucault, Derrida, Deleuze , etc sob o rótulo de pósmodernos, mesmo quando o rótulo não encaixava perfeitamente. Andreas Huyssen afirma que:

Em si, isso não reduz o poder da teoria. Mas faz com que haja uma espécie de mixagem em que a linguagem pós-estruturalista não está em sincronia com o corpo pós-moderno.(HUYSSEN, 1991, 62) 
Huyssen, como outros críticos dessa "ligação de ocasião", quase que apenas circunstancial, do pós-estruturalismo com o pós-modernismo, insistiu em considerar esta linha de pensamento crítico uma arqueologia da modernidade: os objetos de análise, os procedimentos mais básicos, as categorias mais fundamentais da teoria pós-estruturalista, todos seriam derivados de um olhar predominantemente voltado para a modernidade e para os modernismos. O pós-estruturalismo seria, então, uma fronteira da modernidade (com tudo o que implica nessa condição de fronteira) e não a encarnação teórica do pós-modernismo; por mais que por ser um modernismo nos seus limites carregasse necessariamente um potencial autodestrutivo e autocrítico, marcado pela transgressão dos limites da linguagem. Não é tão fácil, todavia, dissociar o chamado pós-estruturalismo do pós-modernismo e da pós-modernidade. Especificamente os conceitos e teorias derivados desta linha teórica é que deram sustentação filosófica ao pós-modernismo, e, em vários sentidos, a várias das configurações contemporâneas dos EC.

Além dos discursos sobre o pós-moderno, derivados do debate sobre e com a teoria francesa, outras tendências importantes dos EC contemporâneos são a teoria pós-colonial e a teoria crítica que lida diretamente com as questões das minorias e das micropolíticas. A produção cultural da periferia e o debate sobre ela têm consolidado um viés nos EC: a definição de política (teórica e prática) das minorias. As diferenças culturais precipitam um imperativo para o teórico da cultura, que é preparar uma moldura conceitual que revise e recoloque o papel das minorias, dos subalternos, dos periféricos, do que era chamado de Terceiro Mundo na reordenação "global" da cultura. Precisamente no corpus dos Estudos Culturais contemporâneos e das teorias pós-colonialistas é que veremos as análises mais agudas dos processos dessa reordenação.

Os Estudos Culturais e o pós-colonialismo reafirmam, como antes as teorias e políticas terceiro-mundistas, mas de modo muito mais articulado e sistemático, o papel do periférico na História e a própria História periférica. O lugar do periférico na configuração da cultura contemporânea e na crítica, análise e teoria dessa cultura, portanto, está muito diferenciado em contraste com as disciplinas mais tradicionais. É um ponto de observação privilegiado no sentido da multiplicidade desse espaço intermediário. É evidente que muitas outras teorias e estéticas já desenvolveram e 
problematizaram conceitos como representação, identidade, alteridade, hibridismo, colonização, Ocidente, Oriente. Entretanto, a partir dos Estudos Culturais tais elementos e noções são colocados num marco de referências que, ao invés de simplesmente inverter ou descartar termos e hierarquias, vai questioná-los na sua essência e na sua malha de interrelações, vai pensar as condições de possibilidade, continuidade e utilidade da sua construção. Os Estudos Culturais trabalham precisamente com essa possibilidade da superação de esquemas binários (cópia/original; modernidade/tradição; centro/periferia), mas não com a sua inversão radical (BHABHA, 240).

Para os Estudos Culturais, o debate sobre o pós-moderno serve, apesar da multiplicidade de "encarnações", propósitos e definições, fundamentalmente para designar e dar corpo à crise de centralidade pela qual passa o Ocidente. Insistimos que tal crise é a pedra de toque da teoria contemporânea, que vai repensar a diferença cultural a partir do descentramento pós-moderno.

Os discursos tecidos num entrelugar, as teorias baseadas nas culturas periféricas, as políticas da diferença apontam para um entrelaçamento entre experiência cultural, a prática da crítica e o terreno da política, para um transbordamento da cultura para fora do campo estético. Indicam que os Estudos Culturais formam um campo fortemente marcado pela utopia: a utopia dos discursos da heterogeneidade, dos sonhos singulares, de um entrelugar complexo e híbrido. $\mathrm{Ou}$ seja, discursos que, num paradoxo sempre intrigante, almejam uma certa harmonia nas diferenças.

\section{Terceiro Mundo e Terceiro Cinema}

Essa mesma moldura apresentada acima poderia ser facilmente aplicada à história do cinema: movimentos que refletiam as profundas transformações pelas quais o mundo estava passando e que por sua vez também definiam o espírito da época de modo paradigmático. Das novas ondas aos novos cinemas, passando pelos neo-realismos e cinemas livres, especialmente a partir do final dos anos 50, o cinema (e o estudo do cinema também pode ser incluído numa percepção mais abrangente do fenômeno) passa a ser fortemente marcado pela política. Destacamos a influência 
que o conceito de Terceiro Mundo teve para a construção dos imaginários cinematográficos (não apenas os cinematográficos, é evidente).

O termo Terceiro Mundo começou a ser utilizado por demógrafos e geógrafos franceses nos anos 50 como a outra peça no quebra-cabeças do mundo pós- Segunda Guerra Mundial, em relação a um Primeiro Mundo capitalista e ocidental e um Segundo Mundo socialista. Nesta época, talvez com o valor de eufemismo, ele substitui a idéia mais difusa, menos organizada e mais traumática de "países pobres". A partir das lutas de independência das colônias européias na África e na Ásia, o termo adquire um certo prestígio. A unidade pretendida por ele traz, pois, em seu bojo, uma dimensão revolucionária. A dimensão de relevar as diferenças em prol de um ideal libertário legitimaria então a noção de Terceiro Mundo. Na conferência de Bandung, em 1955, o termo teve a sua primeira expressão política oficial, quando se reuniram todas as nações "não-alinhadas" - ou seja, nem ao Primeiro Mundo, nem ao Segundo. (HARLOW,1987)

A concepção libertária de Terceiro Mundo foi favorecida por paradigmas apresentados nos séculos e, principalmente, nas décadas anteriores: pelo existencialismo, pelas leituras que o Terceiro Mundo fez de Sartre, pelo próprio declínio do humanismo (JAMESON, 1984). Um modelo estabelecido por Frantz Fanon, em Les damnés de la terre, de 1961, obra precursora, em certa medida, da unidade, do "chamamento" ao Terceiro Mundo. Um chamamento de luta, de violência, de uma relativa rejeição dos cânones "ocidentais": uma tentativa de livrarse de certas concepções de cultura, sociedade, história, política... O impacto da visão de Fanon é notável por sua disseminação em todo(s) o(s) mundo(s) (especialmente no "Terceiro", obviamente). A sua influência deve-se tanto à sua teorização sobre descolonização e violência, à sua apreensão do espírito da época e à denúncia antiimperialista que ele inspira, como à sua capacidade de pensar essa descolonização como construção violenta sim, mas com fins utópicos.

Uma provável unidade terceiro mundista possibilitaria a atuação destacada do Terceiro Mundo no "mundo", na ordem internacional. A voz coletiva desse legado de pobreza e exploração se fez ouvir mais forte durante os anos 60 e com as revoluções vencedoras e também as fracassadas que assustam e maravilham este "mundo". Desde o pós-guerra, a Nouvelle Vague francesa revolucionando 
esteticamente o cinema e o neo-realismo italiano e o Free Cinema Britânico mostrando uma Europa quase terceiro-mundista, os estudantes em Maio de 1968, o movimento norte-americano contra a Guerra do Vietnã,os hippies americanos "instituindo" uma contra-cultura. O "mundo" viu Cuba, as guerrilhas, Che, a Revolução Cultural chinesa: A cultura mundial acabou sendo influenciada e influenciando os movimentos políticos simultaneamente.

Ou seja, o conceito de Terceiro-Mundo serve a partir dos anos 60 - para além das delimitações eufemísticas e conservadoras da geografia contemporânea para estabelecer uma unidade de cunho libertário e idealista. Os processos de descolonização, de conscientização social e de luta política desencadeados no globo ao longo deste período não se esgotam em si mesmos: eles fazem parte da grande crise da modernidade que implica também numa reorganização (ou desorganização) cultural em todos os cantos do globo. Uma das mais diretas e evidentes influências da consciência terceiro-mundista (e todas as suas implicações) foi a própria constituição da idéia de Terceiro Cinema.

De acordo com a idéia de transformação da sociedade pela conscientização trazida à tona pelos ideais terceiro-mundistas, os principais temas dos filmes do Terceiro Cinema vão ser a pobreza, a opressão social, a violência urbana das metrópoles inchadas e miseráveis, a recuperação da história dos povos colonizados e oprimidos e a constituição das nações. Os praticantes do Terceiro Cinema recusam adotar um modelo único de estratégias formais ou transformar-se em um "estilo", embora isto não tenha significado que eles estivessem alheios ao cinema mundial e à idéia de um modelo, se aberto, ao menos em linhas gerais unificador.

Ou seja, além de buscar os temas nas esferas marginalizadas da sociedade, estes cineastas demonstram laços estilísticos estreitos com o neo-realismo italiano e a Nouvelle Vague francesa. Tais influências vão ser sentidas em dois níveis principais: o neo-realismo italiano serve como proposta similar de abordagem formal que pode ser aproveitada por sua simplicidade, baixo custo e linguagem direta; e a Nouvelle Vague enquanto afirmação do "cinema de autor", o que possibilita a consolidação das linguagens individuais dos principais expoentes do movimento. A partir desses elementos, emerge um conjunto de procedimentos mais ou menos comuns à maioria dos diretores engajados na denúncia social. 
Por um lado, técnicas abertas e simples (em contraste com sofisticação tecnológica do modelo de estúdios hollywoodianos), por outro, a veiculação de idéias complexas e revolucionárias, como a liberação terceiro-mundista, as teorias do subdesenvolvimento, etc. O Terceiro Cinema pode ser visto, assim, como um statement sobre o cosmopolitismo de duas vias: primeiro, como interpretação latinoamericana das últimas tendências estéticas européias (cosmopolitismo "à moda antiga") como o neo-realismo e a Nouvelle Vague. Segundo, como negação desse cosmopolitismo tradicional onde existe um Centro metropolitano definindo o que os povos subalternos devem fazer. No Terceiro Cinema, os destituídos são colocados no Centro. A atitude é de rebeldia e não apenas a rebeldia estética, mas a rebeldia política e de ação social.

É irrefutável que o Terceiro Cinema, que teve na América Latina seus primeiros e talvez mais eminentes cineastas e teóricos (Fernando Solanas e Octavio Getino na Argentina; Glauber Rocha no Brasil, Jorge Sanjinés na Bolívia) (DISSANAYAKE e GUNERATNE, 2003, 3), teve seu período áureo exatamente na mesma época em que o chamamento terceiro-mundista ecoava com mais força, ou seja, durante os anos 6o, ápice da contracultura e momento crucial de formação, prática e teorização de uma "estética geopolítica" (JAMESON, 1995). E assim como as utopias terceiro-mundistas foram definhando ao longo da década de 80, também a noção de Terceiro Cinema foi gradualmente perdendo lugar (tanto nas salas de exibição, como na própria pesquisa na área de cinema e audiovisual).

Os anos 80 foram quase definitivos para o "Terceiro-Mundismo" (para o conceito de Terceiro Mundo, para a estética terceira-mundista, para a prática revolucionária terceiro-mundista que restou dela). Primeiro porque foi a partir desta década que se questionou teoricamente com mais ênfase a validade do termo, justamente a partir dos Estudos Culturais e do pós-colonialismo. Também nos 80, começamos a assistir ao ocaso do Segundo Mundo (culminando na sua "dissolução" como Segundo Mundo, simbolizada pela queda do Muro de Berlim, em 1989). O não-alinhamento às grandes potências se esgotou como estratégia de resistência $\mathrm{e}$ oposição ideológica. Por isto também, a estética terceiro-mundista radical pereceu e outras "terceiras margens" foram buscadas, já que não parecia funcionar mais a 
apologia do oprimido. Talvez tenha acontecido a desilusão final do Terceiro Mundo como categoria unificada e indivisível:

The term Third World, post-colonial critics insist, was quite vague in encompassing within one uniform category vastly heterogeneous historical circumstances and in locking in fixed positions, structurally if not geographically, societies and populations that shifted with changing global relationships. (DIRLIK, 332)

\section{Convergências contemporâneas nas margens}

Se os anos 80 representaram uma espécie de vácuo para o Terceiro Cinema (e para a estética terceiro-mundista) como um todo, a segunda metade dos 90 significou a reemergência de muitas das questões ligadas ao imaginário políticosocial das décadas de 60 e 70 . Entretanto o que podemos chamar de "reinsurgência da periferia" ou "reencenação da subalternidade" se deu de maneira muito distinta do discurso engajado precedente.

Poderíamos dizer que, de maneira muito geral, os anos 80 foram um período no qual não parecia fazer parte do dominante cultural dos principais países "terceiromundistas” produtores de cinema (em especial a América Latina) a representação de aspectos políticos e a tematização das identidades nacionais e das realidades mais desoladoras foram quase que totalmente abandonadas e quando ainda se insistia numa temática mais próxima àquela do Terceiro Cinema original, o resultado refletia uma espécie de esvaziamento. Contudo, a retomada representada pelos anos 90 representa menos uma drástica mudança e mais um gradual amadurecimento dos preceitos culturais (e até teóricos) anteriores. As próprias tendências acadêmicas mundiais rumo a uma valorização do ex-cêntrico, do periférico, do marginal (BHABHA, 1998) tiveram um efeito revigorante sobre os cinemas nacionais. Até mesmo os renovados paradigmas filosóficos e sociológicos trazidos à tona pelos Estudos Culturais e teorias pós-coloniais, embora de forma muito lateral e específica, contribuíram não apenas para o redespertar do interesse no agora chamado World Cinema, mas para revitalizar os instrumentos de leitura e recepção dos filmes.

O cinema periférico tem emergido nos últimos anos como uma espécie de moda cultural dos grandes centros. Está quase que automaticamente preservado o “direito de exibição" por essas “denominações de origem”. Esse lugar de destaque conquistado sobretudo a partir do final da década de 90 e início dos 2000 com filmes 
como O Balão Branco (Irã, 1995); Central do Brasil (Brasil, 1998), Amores Brutos (México, 1999), Nove Rainhas (Argentina, 1999), Amor à flor da Pele (Hong Kong, 2000) - não é definido por uma unidade estética ou temática (embora possamos agrupar algumas recorrências, evidentemente, ao longo das duas últimas décadas), mas sim pela vaguíssima possibilidade de redelineamento da noção de Terceiro Cinema através do termo World Cinema e do conceito de multiculturalismo.

Entretanto, podemos apontar (de modo talvez excessivamente panorâmico e superficial) algumas características do antes chamado Terceiro Cinema a partir dos anos 90:

1. Há uma busca explícita pela inserção no mercado de cultura mundial. Tal inserção está, de certo modo, garantida pelo espírito do tempo, um momento bem propício no qual a cultura periférica não apenas passa a ser percebida pela cultura central, como passa a ser consumida na metrópole; o ponto em que a diferença cultural passa a ser encarada quase como estratégia de marketing.

2. É evidente também a forte inclinação para o passado, numa tentativa explícita de rearticulação da tradição. Que muitas vezes parece ser o sinal de uma nostalgia, o sintoma de uma saudade cultural. Como também pode ser a explicitação de um diálogo dessa tradição com a modernidade, pode ser a subversão da idéia de identidade nacional tendo em vista um cosmopolitismo ex-cêntrico. Esse cinema apresenta, num direto contraponto com a cultura yuppie, consumista e frívola de um primeiro pós-modernismo dos anos 80 , uma tentativa de rearticulação com a tradição, e afirma constantemente as narrativas da nação, mas freqüentemente procurando subverter noções fechadas sobre identidade. O passado, a tradição, a História passam a ser material fundamental dessa produção cinematográfica.

3. Tais opções sugerem um segundo pós-modernismo cinematográfico ligado ao Terceiro Cinema, em oposição ao preexistente nos anos 80. Um pósmodernismo marcado pelos princípios de "recuperação", de "reciclagem", de "retomada" da tradição, da história e de um certo autoexotismo em oposição ao gosto pelo estrangeiro, pelo cosmopolitismo tradicional, pelo discurso internacionalista do pós-modernismo da década anterior. Nesse sentido, vão sendo definidas “modernidades periféricas". 
4. O cinema contemporâneo se volta para a documentação do pequeno, do marginal, do periférico, mesmo que para isso se utilize de técnicas e formas de expressão (às vezes até equipe de produção) de origem central, metropolitana, hegemônica.

5. Ou seja, a "diferença", a história e a identidade periféricas tal como representadas pelo cinema contemporâneo tornam-se peças constitutivas da tentativa de integração ao modelo capitalista global A idéia de articulação periférica e da identidade nacional com uma roupagem "globalizada" nesses filmes não só faz parte do establishment, como mostra de forma muito clara o funcionamento do mercado cultural globalizado.

6. A cidade desenhada pelo "novo" Terceiro Cinema pouco tem a ver com os clichês recorrentes (um exemplo muito interessante está na forma como Buenos Aires é representada no filme Felizes Juntos, do chinês Wong Kar Wai, que mostra um casal gay, originário de Hong Kong, em férias em Buenos Aires. Depois de gastar todo o dinheiro que tinham, passam por uma série de contratempos que os impede de voltar para a Ásia. A idéia aqui foi subverter o olhar, foi mostrar uma tradução asiática da América Latina. Cosmopolitismos periféricos ao pé da letra.). E é precisamente através de imagens urbanas pouco usuais e da opção estética pelo pequeno, pelo detalhe, pelo periférico que os filmes constroem uma representação alternativa, mais plena de nuances e mais complexa do mundo contemporâneo.

7. Remontando, em certa medida, à temática do Terceiro Cinema original (desvalidos, subalternos, excluídos), porém sem deixar de privilegiar os aspectos técnicos do cinema (a maior parte da produção contemporânea periférica tem imagem e som comparáveis às grandes produções do cinema mainstream), o cinema periférico contemporâneo estaria atualizando o discurso do terceiro-mundismo (ou seja, uma maneira pós-moderna de falar da subalternidade, do periférico) retirando dele o tom politicamente engajado explícito, a "estética da fome" e a técnica propositadamente limitada.

É possível contudo enxergar nessas vias tomadas pelo Terceiro Cinema, especialmente para o argumento desenvolvido aqui, não somente a vaga delimitação de uma possível estética contemporânea - e que talvez pudesse ser aplicada a outras 
esferas da cultura -, mas também as evidências da necessidade de um instrumental teórico suficientemente abrangente, flexível e múltiplo para compreendê-lo - e os Estudos Culturais, desde suas encarnações mais tradicionais, desde os estudos de audiência, passando por suas versões pós-modernas e pós-estruturalistas, até a as visões mais correntes do multiculturalismo, seriam, indubitavelmente, a referência indispensável para isso. Por sua vez, o cinema tem sido o cerne de uma significativa parcela das publicações recentes na área de Estudos Culturais (como por exemplo SHIEL e FIZTMAURICE, 2001; BARBER, 2002; VITALI e WILLEMEN, 2006; GRANT e KUHN, 2006; BADLEY, PALMER, e SCHNEIDER, 2006, entre muitos outros). Há, portanto, um notável interesse das teorias da cultura em dar conta dessa produção cinematográfica, reconhecendo nela simultaneamente um corpus relevante de objetos materiais do contemporâneo (passíveis de análise formal) e um campo de representações (e muitas vezes também de práticas) de subversão e resistência subculturais.

\section{Referências:}

BADLEY, Linda, PALMER, R. Barton e SCHNEIDER, Steven Jay (eds). Traditions in World Cinema. Edimburgo: Edinburgh University Press, 2006.

BARBER, Stephen. Projected Cities. Cinema and Urban Space. Londres: Reaktion Books, 2002.

BHABHA, Homi K.. O local da cultura. Belo Horizonte: Editora da UFMG, 1998.

DIRLIK, Arif. "The Postcolonial Aura: Third World Criticism in the Age of Global Capitalism", Critical Inquiry 20 (1994), pp.328-356.

DISSANAYAKE, Wimal e GUNERATNE, Anthony (orgs). Rethinking Third Cinema. Londres/Nova York: Routledge 2003.

DURING, Simon (ed). The Cultural Studies Reader, Londres/Nova York: Routledge, 1993.

GRANT, Catherine e KUHN, Annette (eds). Screening World Cinema. Londres/Nova York: Routledge, 2006.

HARLOW, Barbara. Resistance Literature. Londres/Nova York: Methuen, 1987. 
HOLLANDA, Heloisa Buarque de. Estudos Culturais na Academia. In: Seminário Trocas Culturais na Era da Globalização, 1996, Rio de Janeiro. (http://www.ufrj.br/pacc/global.html)

HUTCHEON, Linda. Poética do pós-modernismo - História, Teoria, Ficção. Rio de Janeiro: Imago, 1991.

HUYSSEN, Andreas. "Mapeando o pós-moderno" in Pós-modernismo e política (Heloísa Buarque de Hollanda, org.). Rio de Janeiro: Rocco, 1991.

JAMESON, Fredric. The Geopolitical Aesthetic. Cinema and Space in the World System. Londres/ Bloomington: British Film Institute / Indiana University Press, 1995 .

. "On Cultural Studies", Social Text 34, vol. 11, nº 1, 1993, 17-52. "Periodizing the 6os". The 6os without apology. Minneapolis: University of Minnesota Press, 1984. São Paulo: Ática, 1996.

MOREIRAS, Alberto. A exaustão da diferença. A política dos estudos culturais latino-americanos. Belo Horizonte: Editora da UFMG, 2001.

PRAKASH, Gyan. "Postcolonial Criticism and Indian Historiography", Social Text 31-32 (1992), pp.6-18.

SHOHAT, Ella e STAM, Robert. Multiculturalismo, cine y medios de comunicación. Crítica del pensamiento eurocéntrico. Buenos Aires: Paidós, 2002.

VITALI, Valentina e WILLEMEN, Paul (orgs.). Theorising National Cinema. Londres: British Film Institute, 2006. 